\title{
Attaining Fluency in the Language Classroom at College Level
}

\author{
K. Jeya Gowri, M. Ilankumaran
}

\begin{abstract}
The popularity of English language as well as its practice as a link language have received a paramount importance in every field all around the world. Students face many problems in using English language during their higher studies. People spend huge money for spoken English classes for getting good jobs. This aspect promotes the language to untangle the problems of people in language proficiency. Even after attending those classes, no change can be seen in the ability of the students in the language. This is because the improper curriculum from schooling to the tertiary level. Not all the English teachers can write the letter or CV properly. This is because of the poor curriculum. This paper deals with the challenges faced by the students during the college level. Moreover, this paper analyses the causes and effects of the problems faced by students and ability in attaining the language efficacy at tertiary level. Proper curative measures are mentioned for the effective rectification of these complications. The capacity to comprehend the learning styles of the pupils can upsurge their involvement in learning. The tutors have to amend their teaching style so that it will be consistent with the students' way of learning in the classroom. One of the most vital applications of learning style create an easy way for the teachers to integrate the learners into their teaching. Numerous probable teaching styles have to be adopted by the teachers to support the learning of the students. The instructors can integrate these learning methods in their course activities so that the boys/girls will be able to flourish in their classes. This article is an investigation of learning techniques for the English language students in the college classroom. The aim of this analysis is to intensify the faculty consciousness and recognizing the different ways of learning and the effective teaching process.
\end{abstract}

Keywords--- Language Learning, Problems, Curriculum, Efficacy, Proficiency, Effective Teaching, College Level.

\section{INTRODUCTION}

The importance of Spoken English is much valued when a person comes to get survived in foreign countries. Even in the multilingual countries like India, it helps to make a conversation at time of necessities. The language is concerned to be essential and taught as a compulsory course in every school. The outcome of learning in schools does not make a student completely fluent in their communication. Some schools are unsuccessful in learning English at the expected level. So it is crucial to discover the causes for the poor outcomes of the learners in English. Language has distinctly played a main role in the advancement of human civilization. It is a vital requisite of the society. It is a developed skill so learning the language is allied to the foundation of certain practices. Learning a second language, in the formal environment, it becomes essential to ponder the principles of features affecting while language learning.

Revised Manuscript Received on July 10, 2019.

K. Jeya Gowri, Research Scholar in English, Noorul Islam Centre for Higher Education, Kumaracoil, Thuckalay, Tamilnadu, India. (e-mail: jgowri427@gmail.com)

M. Ilankumaran, Professor of English, Noorul Islam Centre for Higher Education, Kumaracoil, Thuckalay, Tamilnadu, India.

(e-mail: mikumaran@yahoo.com)
Learning a second or foreign language is considered to be a language education. The vernacular medium students and process of habit formation are the core factor which affects English language learning. In schools, the vernacular medium students learn the subjects, reading and writing in mother language. This process affects their attainment in listening and speaking in English. Thus, the students infrequently get the opportunities in practicing or speaking English at home.

There are also other factors which affect language learning, they are psychological and sociological elements. Improper motivation takes more time in learning the second language. The readiness and involvement of learners in learning a new language depend on the facilities and opportunities of environment wherein the vernacular medium students may suffer. In second language learning, the students who are studying in the vernacular medium lag behind due to their educational status and socio-economic with some exceptions.

Language learning strategies have been notoriously difficult to define. One of the earliest researchers, Rubin provided a broad definition of learning strategies as "the techniques or devices which a learner may use to acquire knowledge". Pupils learn the information through understanding its significance by seeing the materials existing in the classroom. If they are not involved in the information presented, they will not learn it. To attain the crucial aim of student learning it is essential to practice a combination of teaching approaches and to create the classroom setting as inspiring and communicative as possible. Students learn in different methods. Certain learners are visual, while others are auditory or kinaesthetic learners. The visual learners can easily learn through visuals like images, diagrams and visual aid. Aural that is the auditory learners can learn only through paying attention to speech, talks or lectures and reading. Kinaesthetic learners can learn only by experiencing the activities. In this research article, the meaning of learning styles, common learning styles, about the visual, auditory, and kinaesthetic learning styles have been discussed. Then, the use of learning styles in the classroom, significance of learning styles, the benefits of recognising learning styles have also been discussed.

\section{ENGLISH IN THE EXISTING CURRICULUM IN INDIA}

The Act of Parliament accepted English as the Associate Official Language in 1963. Kothari Commission (19641966) has placed English in the School curriculum. In most of the Indian states, the school curricula have been framed based on the references of Kothari commission.

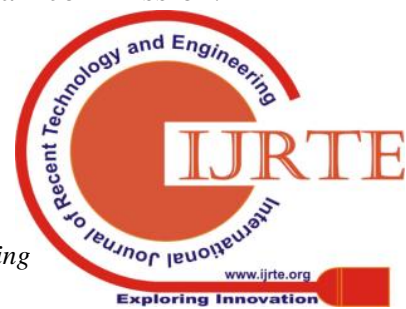


In India, English is taught as practical efficacy and as a link language chiefly for knowledge and understanding. The native medium students are not well exposed to the language. The reason was that they were taught English as the only subject and not as a language and they learned their native language as a subject. Those students may have sufficient understanding and knowledge on the subject but they lack their confidence to express it for communication purpose. They also feel alienated when they meet different levels of students at tertiary level performing well in the class and feel discouraged and do not show themselves confidently during debates, discussions, interviews, and other vital day-to-day communications. If proper exposure is experienced by those students, it would be helpful for them to develop their skills in language learning without any complex.

Thorndike's theory, which was afterword supported by Woodworth, can be used to develop the vernacular medium students to speak English. This theory gives an opportunity for the transmission from listening to speaking skill to the particular degree. There are equal elements like the usage of pronunciation, vocabulary, comprehension, etc. These elements are indistinguishable in both the skills. The aims, interest and habits in the conditions also enable the process of learning.

In the language learning field, communicative approach is the recent invention which helps the students to develop their communicative skills. It also escalates the fluency and accuracy of the language. This approach helps the native medium students to develop their language learning skills. Communication and interaction is possible through this approach. Thus, the pupils indulge in various activities based on this approach which is important in developing their speaking skills in English. Although the English text book covers sufficient activities of communication, there is no adequate attention paid by the trainers and learners. If proper care is taken towards the students through these activities using this approach, it will help them to develop their communication skills. Furthermore, the pupils have to be trained in communication with collection of jargons, articulation and confidence. These elements help them to improve their day-to-day English communication during the course of their life.

\section{THE PROBLEMS OF TEACHING ENGLISH IN HIGHER EDUCATION}

English plays an important role in India for years in every field. In college, the teachers of English has to face a host of problems, making their task a formidable challenge. Students joining college or university are expected to have learnt about 2500 English words along with the sentence structure of about 275. They are also expected to have an adequate knowledge in reading, writing and speaking the English language. In reality, most of the college freshers are less standard in their language skills. According to Mrs. Helen Bernard, the vocabulary gained by the average fresh learners in college is about 1500 words. Most of the college students make mistakes in speech as well as writing the language. This is highly due to the ineffective teaching of English language at the school level. The majority of

teachers in Indian schools have poor command over the language in speaking as well as writing skills.

In schools, the teaching is mostly of examination oriented and thus most of the portions in the syllabus are left uncovered. For instance, the syllabus of English language stresses more on the aural-oral skills but less importance is given to the skill and it is not tested in schools. Thus, the students lack the fundamental and practical exposure on the speaking skills of the language which creates a sense of fear over speaking the language among the students of making errors and being embarrassed in front of the college classroom environment. Almost every school in India follows the Structural Approach in the classroom which is taught through the traditional methods such as Grammar Translation Method. On the contrary, the teachers do not realise the fact that these are much conventional and considered to be one of the oldest as well as the less effective methods.

Another factor responsible for the poor language in the Indian schools are that pupils are taught in their mother tongue. The target language is used only side by side. This factor results in poor command over the English language in the college level and also they not prepared for the change from the vernacular to English medium of instruction. The English teachers in college have to correct the students' wrong habit of writing and speaking as well as the sentence structures on account of the inefficient teaching in schools. They have to raise the standard level of the students which enables them to follow and understand the lectures, participate in seminars and discussions. Thus, the students develop their proficiency in the language over years.

Many English teachers have the wrong perspective of making the students get passed in the examinations. Other factors include the crowded classroom setting with lot of students. Under such condition, it is impossible for the teacher to paraphrase the text and dictate the note to score good marks in the examinations. Unfortunately in most of the Indian colleges, the teachers employ lecture method in the classroom. They just deliver the materials that they have prepared for the students in the class. The lecture method may be effective in the content subjects like English Literature, History and Political Science. This method is considered to be less effective to develop the language skills for the students of college level.

The above are some of the problems faced by the students. There are some students who are quite good in English. If such students are handled properly by the teachers, they can attain the skills of language. The average students know the mechanics of the language and have the limited vocabulary knowledge. Most college students know the rules of English grammar, even though they follow the wrong usage of language just because of the lack of practice. The teachers can provide remedial teaching for the students. Most of the students are hardworking and aware of the significance of English language with regard to their future career. 
The only factor which holds the students back from attaining the language fluency is their hesitancy in speaking the language because of fear of making mistakes. Once when the teacher helps the students to battle such diffidence from them, they will be able to remove their psychological barrier from speaking the language fluently. The teachers have to improve their methods of teaching language by keeping it as a tool of communication.

\section{PROBLEMS IN LEARNING A SECOND LANGUAGE}

Students face numerous challenges in learning English as a second language. They commit errors in grammar, pronunciation, usage and vocabulary. They also encounter the interference of native language in the usage of English. Even the language policy that is the curriculum is concerned to be one of the problems affecting students from acquiring the language. Comparing to the students of urban areas, the rural area students have poor exposure in learning language whereas the urban students are exposed with a lot of utilities to learn the language. So the opportunities become rare in the case of the students from rural areas. The main hurdle for learning English is that there is no acquainted atmosphere to learn the language. There is no exposure outside the classroom. In other words, the students do not understand the instant necessity to acquire the language. Besides these problems on the part of students, the curriculum also plays a major role in the attainment of the teaching and learning problems of English language can be identified in Iran and India.

The students, when they move to tertiary level realise the need of the fluency in English, look forward to develop the language. On the contrary, the fact is that they do not know where and how to start to improve in it. In many cases, students do not show their interest to learn the language in English classes. Many other students fail to learn it without comprehending the strategy in it where some students accomplished it successfully. The fact is that strategy is not taught in schools as well as in colleges. (Akbari, 2014) Teachers fail to teach them the effective methods of learning the language in the classroom. Thus, it ends up with mugging up the language. It has been claimed that autonomous learning is vital for language learners for the following three motives. The first reason is that because of the difficulty of task in learning, and the second reason is that self-learning would stimulate the learning efficiency of the students. The third reason is that the learners develop their interest in the course of learning.

The other aspect is that the students' complexity in learning English consists of acquiring ample of words and grammar rules which could only be memorized (Oxford 2001). The factors for the struggle of the English language learners may also be because of the different educational background. For instance, the students who hail from rural areas do not expose to wide range of the language. In the crowded classrooms, the students do not get individual attention which results in the lack of listening. It is because of the disinterest in learning. Some schools give less prominence to English subject comparing to other subjects. This stops one from realising its significance as a language. MirzaeiRizi (2014) et al. states that the poor

communication means in every field for survival. It is the fault of the educational system that the students are made to be prepared from the perspective examination. Thus, their concentration moves to getting highest marks rather than learning it by comprehending the subject. In this way, they do not get any internal motivation. According to the Indian curricular setting, reading and writing skills are given importance rather than listening and speaking skills. This priority over the former skills make the students know the importance of the latter skills.

\section{GENERAL PROBLEMS OF TERTIARY LEVEL STUDENTS IN LEARNING ENGLISH}

Generally, the English language learners encounter the problems in speaking English confidently and fluently. In the case of tertiary level, the students face the new environment which cause them fear and dilemma. In college, an individual meets different ability of students hailed from different board of schools. In this circumstance, the students who have poor intelligence in English language cage themselves by being an introvert. The influence of the native is the main factor in this circumstance. This condition stops them from learning English because of their lack of confidence. Apart from being an introvert, when they try to acquire the language they face complications such as poor vocabulary, poor listening facility which are the negatives for good speaking, low educational background of the family members, educational system without much focus on speaking skill and no provision of separate English speaking classes in schools. This is one among the factors affecting the students at tertiary level in learning English. Speaking is vital and basic method of communication in society. Speaking well has a vivid influence on individual's life.

- Defective Teaching Methods is one of the reasons but the fact is ignorance of the teachers in applying the teaching method in the classroom causes disinterest in learning among the students. Thus, the teaching becomes ineffective.

- Passiveness to New Procedures and Techniques is another reason where some teachers fail to apply these procedures in teaching language because of the ignorance.

- Crowded Classroom leads the teacher not to pay attention to the individual student. English teachers encounter a number of challenges in controlling the big classroom.

- The Syllabus of English is purely based on the examination point of view and does not motivate the learners in developing their communicative skills which confine them to learn it in the perspective of examination.

People who can speak English fluently is assumed to be knowledgeable in India. It is considered to be an obsession rather than a compulsion. It is compulsory in every school to have English as a subject. As it is beneficial for getting good jobs, every college provides education in English. 
In most of the schools, English has been taught as a subject rather than a language. It makes the students fail in communicating fluently in English. The main factor is that it centres around textbooks than focussing on communication practice for a good fluency in English.

In India, there are ordinarily different types of schools regarding English language teaching. English medium schools teach mother tongue merely as a subject, keep it as the medium of instruction for all the subjects. Even though English has been made compulsory in many schools from early stage to the higher level, the question arises about the change of learning English during the transitional period that is from one level to the other. In this transitional stage, the students of second language move towards experience and the practical source of learning English. Thus, the method of teaching decides the quality of the school.

English language teaching in India varies in its standards according to the states. As a result, it produces the children with poor as well as good English language. As the students were motivated to memorize the subjects for achieving good marks, they lack the power of communicating in English fluently. In future, the high school students' transition to college level of education make them realize that the good command over English is necessary for getting good jobs. They also realise at this juncture about the necessity of English because, at the college level, English is the mandatory medium of instruction. The lack of exposure to communication creates an inferior feeling to communicate in English. At the stage of transition, the learners of English feel difficult to acquire the language. The school as well as college experiences exist with different kinds of students; students from rural and urban area, students who studied from Tamil medium to English medium. The other problem that the students fail to acquire the competency in English is because language is taught by the rules and learnt by habit of memorizing it. Some of the factors are discussed as follows.

\section{Lack of Clear System}

One of the main reasons for the poor standard of English is the lack of clear policy. The teaching and learning of English have been changing. Though English is taught as a compulsory subject, only the pass mark is taken into consideration. The Government has decided not to consider marks of English as essential for admission into a university course. Thus, the students give more attention to scoring best marks in other subjects.

\section{Problems Related with Different Students}

Most of the students in India do not get opportunities to speak in English. The rural students get less chances to speak or listen to classes in English. Even in the rural areas, they learn all the subjects in the vernacular language. In this situation, they expose much with the mother tongue and results in the poor competency in English. Different students face difficulties in learning English depending on their capabilities. Learning unknown vocabularies daily, reading books and newspaper, learning pronunciation, listening and thinking in English improve their competency. Some pupils may struggle to learn and do not take any effort to improve their language skill just because of their inferiority complex.
Some others struggle to take any efforts to learn the language.

\section{Lack of Motivation}

Motivation can induce a person to achieve success. Some students are demotivated or may have paid less attention by the teachers. This act may lead them to lack interest in the subject. Some students are weakly motivated due to their social and family background. So the teacher must stimulate such students with motivation. Some teachers have negative aspects on their students. So they do not give any tasks, assignments or challenge to the students. Thus, the students do not get any opportunity to improve in a possible way.It is not easy to learn a second language and so rewarding the students with appreciation induce them to learn the language with interest.

\section{Large Classroom}

The over strength in the classroom is hard for the teachers to pay attention to the students individually. It is also tough for them to pay attention on weak or creative students. As there is no individual attention paid to the students individually, there is no chances for them to develop their intelligence.

\section{Faulty Examination System}

The examination system in this country encourages the students to memorize the subjects. The language and speaking skills are totally neglected. The teachers also never motivate the students to write on their own from the idea they have learned. So the students go beyond on mugging up and producing it on the exam paper.

\section{Remedial Teaching}

Remedial teaching is nothing but a language teaching programme. The students' lack of attention or concentration, their pull of mother tongue, misunderstanding and mishearing of words, word analogy are likely to go wrong in the English language classrooms by the students. These misrepresentations of the target language may become deeply imbedded habits if they are not detected and remedied from time to time. The situations such as wrong methods of teaching, bad models of the use of the language, adverse teaching conditions and the neglect of remedial programme for long period prove that students are discovered to be much below the levels of attaining the competency over the language.

The situation like where the high percentage of students enter the college or university with a low performance in English is great disadvantage to them to carry out their studies.

Hence, it is essential to conduct remedial programmes to standardise students' proficiency in English language. 
VI. CURATIVE MEASURES FOR THE DIFFICULTIES OF ENGLISH LANGUAGE TEACHING AT TERTIARY LEVEL \& RESULTS

- The curriculum for the students have to be updated so that the students search for materials in library or internet.

- For the natural and real language learning, authentic materials such as magazines, newspapers, advertisements etc.have to be involved in the classroom teaching.

- Apart from grammar translation method, the teachers have to teach through TBLT (Task Based Language Teaching) and CLT (Communicative Language Teaching) because continuous teaching makes them feel boring. In this case, these activities interest them to learn the language.

- Using different methods of teaching in class paves the way for effective learning. There are variety of language teaching methods which have to be used widely. The language teaching methods include, direct method, audio lingual method, grammar translation method, oral approach, communicative language teaching, etc.

- It is significant for a teacher to cultivate a rapport with the class which creates an impression of approachable perspective towards the teacher.

- Apart from teaching the students, making a daily conversation improve their language skills.

- The students may have complex ideas within themselves which stop them from learning the language. In addition to this, the students experience different barriers in language learning, this situation can be avoided by using the formal delivery of language without using the regional dialect.

- Mistakes are possible during the course of learning which have to deal with care without punishing or embarrassing the students. Correcting the mistakes have to be handled subtly.

- The teachers have to motivate the communication skills by making an interactive classroom teaching which cultivate their confidence and get rid of their socio psychological complications.

- Teachers have to focus on all set of students, and not only the intelligent and average students. Teachers have to give equal care to all students so as to create a healthy relationship. Weak students have to get more attention from the teachers.

- Punishments need not be done in the classroom, as it would affect the students psychologically.

- It is in the hands of the teachers to create the teacher-friendly environment. A teacher has to motivate the students to communicate in English thereby they will get enough chance for that. The teachers have to make the students participate in peer learning, and other activities to develop communication skills. Thus, the teacher can lead the students to feel at ease from the transitional dilemma.

\section{CONCLUSION}

English language teaching to the college students is bound with the problems of poor motivation, inadequate exposure to the language, poor class room conditions, etc. Effective language teaching is important because it is essential to reach the learners with all abilities. Teachers face many problems in teaching English to the tertiary level students. However, in schools, no effective teaching is done to improve the language. So the teachers in colleges find this as an excuse in handling poor students in English classes. The students should be gradually provided patterns of sentences from simple to difficult to improve their language. They should also try to improve their vocabulary skills to improve their expression. A change in the teaching method have to be imparted through the practical method of teaching which creates interest in students in learning English.

\section{REFERENCES}

1. A Delbio, Dr. M. Ilankumaran, "Theories, Techniques, Methods and Approaches of Second Language Acquisition: A Psychological Perspective" International Journal of Engineering and Technology (IJET) (Scopus Indexed), vol.7 no3.6, July, 2018, pp. 192-197, ISSN: 2227-524X

2. Delbio, Dr. M. Ilankumaran, "Second Language Acquisition Through Neurolinguistic Programing: A Psychoanalytic Approach" International Journal of Engineering and Technology (IJET) (Scopus Indexed), vol.7 no 4.36, Nov. 2018, pp. 624-629, ISSN: 2227-524X

3. Delbio, Dr. M. Ilankumaran. "Process and Techniques to Improve Memory Power in Second Language Aquisition”, Literatures in English for Cross Cultural Communication, Annammal Publications, Nov. 2018, pp. 189-196, ISBN: 978-81-923842-5-2

4. Delbio, Dr. R. Abilasha, Dr. M. Ilankumaran, "Second Language Acquisition and Mother Tongue Influence of English Language Learners - A Psycho Analytic Approach" International Journal of Engineering and Technology (IJET) (Scopus Indexed), vol.7 no 4.36, Nov. 2018, pp. 497-500, ISSN: 2227-524X

5. Abilasha, R. Ilankumaran, M. "Incarnation of ICT in English Language Teaching." Research Journal of English Language and Literature, vol. 2, no. 4, 2014, pp. 216-220.

6. Akbari, Zahra. "Current challenges in teaching/learning English for EFL learners: The case of Junior High School and High School." Procedia - Social and Behavioral Science, 2015, pp. $394-401$.

7. Akbari, Zahra. "The Role of Grammar in Second Language Reading Comprehension: Iranian ESP Context". Procedia - Social and Behavioral Sciences, 2014, pp.122-126.

8. Delbio A, Dr. M. Ilankumaran, 'Pedagogical Approach and Strategies of English Language Teaching through Global Literature' International Journal of English Language and Literature in Humanities (IJELLH) with IF 5.7, vol.6 no.12, Dec. 2018, pp.52-59, ISSN-2321-7065 (Online)

9. Dr. M. Ilankumaran, P. Deepa "Teaching Literature Enhances Communication Skills - A Study with Special Emphasis on Poetry” International Journal of 
Engineering and Technology (IJET) (Scopus Indexed), vol.7 no3.6, July, 2018, pp. 187-191, ISSN: 2227-524X

10. Dr. R. Abilasha, Dr. M. Ilankumaran, 'Developing Communication Skills of Students - An Analysis on Pragmatic Performance', International Journal on Studies in English Language and Literature (IJSELL) with IF 3.537, Volume 6, Issue 7, July, 2018, PP 26-31, ISSN: 2347-3126 (Print) \& ISSN: 2347-3134 (Online)

11. Dr. R. Abilasha, Dr. M. Ilankumaran, 'Psychological Factors Permeating Global Literature - An Overview' International Journal of English Language and Literature in Humanities (IJELLH) with IF 5.7, vol.6 no.12, Dec. 2018, pp.8-16, ISSN-2321-7065 (Online)

12. Dr. R. Abilasha, Dr. M. Ilankumaran, "Business English: The Quintessence of the Corporate World" International Journal of Engineering and Technology (IJET) (Scopus Indexed), vol.7 no 4.36, Nov. 2018, pp. 608-612, ISSN: 2227-524X

13. Dr. R. Abilasha, Dr. M. Ilankumaran, "English Language Teaching: Challenges and Strategies from the Indian Perspective" International Journal of Engineering and Technology (IJET) (Scopus Indexed), vol.7 no3.6, July, 2018, pp. 202-205, ISSN: 2227-524X

14. Dr. R. Abilasha, Dr. M. Ilankumaran, "The Role of Media in Enhancing Communicative Competence of the Learners at Tertiary Level - An Analytical Study" International Journal of Engineering and Technology (IJET) (Scopus Indexed), vol.7 no 4.36, Nov. 2018, pp. 655-659, ISSN: 2227-524X

15. Dr. R. Abilasha, Dr. M. Ilankumaran. "Content Based Instruction: A Tool to Develop Communication Skills", Literatures in English for Cross Cultural Communication, Annammal Publications, Nov. 2018, pp. 175-182, ISBN: 978-81-923842-5-2

16. K. JeyaGowri, Dr. M. Ilankumaran, 'World Literature as a Tool for Learning English in the Classroom Environment' International Journal of English Language and Literature in Humanities (IJELLH) with IF 5.7, vol.6 no.12, Dec. 2018, pp.89-96, ISSN-2321-7065 (Online)

17. K. JeyaGowri, Dr. M. Ilankumaran, "Application of Theories, Techniques, Methods and Approaches to Develop Second Language Skills - A Study based on Transition from Schooling to College" International Journal of Engineering and Technology (IJET) (Scopus Indexed), vol.7 no3.6, July, 2018, pp. 210-215, ISSN: 2227-524X

18. K. JeyaGowri, Dr. M. Ilankumaran, "The Role of Students in Transition from School to College: Different Challenges in ELT" International Journal of Engineering and Technology (IJET) (Scopus Indexed), vol.7 no 4.36, Nov. 2018, pp. 630-635, ISSN: 2227-524X

19. K. JeyaGowri, Dr. M. Ilankumaran. "The Struggling ESL Learners: A Study on Difficulties in Language Learning at Tertiary Level", Literatures in English for Cross Cultural Communication, Annammal Publications, Nov. 2018, pp. 197-205, ISBN: 978-81-923842-5-2

20. K. JeyaGowri, Dr. R. Abilasha, Dr. M. Ilankumaran, "Enriching Cognizance at the Tertiary Level Students During Transition" International Journal of Engineering and Technology (IJET) (Scopus Indexed), vol.7 no 4.36, Nov. 2018, pp. 665-668, ISSN: 2227-524X

21. Oxford, R. Integrated Skills in the ESL/EFL Classroom. ERIC Digest. 2001

22. P. Deepa, Dr. M. Ilankumaran, "Teaching Poetry Enhances Speaking Skills - An Analysis based on Select Poems" International Journal of Engineering and Technology (IJET) (Scopus Indexed), vol.7 no 4.36, Nov. 2018, pp. 619-623, ISSN: 2227-524X

23. S. Sreena, Dr. M. Ilankumaran, 'The Role of Teachers in Developing Second Language Acquisition' International Journal of Research in Humanities, Arts and Science with IF 2.135, vol.2 no.9, April, 2018, pp. 40-43, EISSN: 2456-5571

24. S. Sreena, Dr. M. Ilankumaran, "Developing Productive Skills through Receptive Skills - A Cognitive Approach" International Journal of Engineering and Technology (IJET) (Scopus Indexed), vol.7 no 4.36, Nov. 2018, pp. 669-673, ISSN: 2227-524X

25. S. Sreena, Dr. M. Ilankumaran, "Developmental Speaking as A Strategy to Enhance Communicative Skills - A Cognitive Based Approach" International Journal of Engineering and Technology (IJET) (Scopus Indexed), vol.7 no 4.36, Nov. 2018, pp. 613-618, ISSN: 2227-524X

26. S. Sreena, Dr. M. Ilankumaran. "Developing Communication Skills using Developmental Speakng as a Technique", Literatures in English for Cross Cultural Communication, Annammal Publications, Nov. 2018, pp. 254-261, ISBN: 978-81-923842-5-2

27. Thakur, Jyoti. "Challenges and Prospects in Teaching of English at Elementary School Level". Educationia Confab, vol. 2, no. 1, 2013, pp. 125-133 